argued that this resurgence in interest in colposcopy has stemmed from too loose an interpretation of abnormal cervical smears and the too frequent resort to cone biopsy and hysterectomy. Certainly more conservative methods such as cryosurgery or the laser beam have now become accepted as having an important part to play in the management of cervical intraepithelial neoplasia. ${ }^{7} 8$

In large measure this renewed interest in colposcopy in Britain stems from the pioneer work of Anderson in Edinburgh $^{9}$ and Coppleson ${ }^{1011}$ in Oxford, followed by Jordan, ${ }^{12}$ Singer, ${ }^{13}$ and Crompton and Langley. ${ }^{14}$ Coppleson ${ }^{6}$ has claimed that colposcopy has brought a new precision to our understanding of the life history of cervical epithelium in health and disease; in experienced hands it has much to contribute to clinical practice in gynaecology. Kirkup et al ${ }^{15}$ have recently described 451 patients who were referred to their colposcopy clinic because of abnormal cervical cytology or a suspicious appearance of the cervix. Their study confirmed that colposcopically directed biopsy specimens may be used with assurance in reaching an accurate and safe diagnosis in patients with abnormal smears. The upper limit of the lesion was out of sight in the endocervical canal, making a diagnostic cone biopsy necessary in $8.9 \%$ of their cases. This standard of service requires a highly trained colposcopist continuously concerned with the investigation and management of large numbers of patients. The danger is of "underdiagnosis" rather than "overdiagnosis." This is unlikely to happen with skilled colposcopists but those with less experience may advise conservative treatment (local biopsy or cryosurgery) when the lesion warrants further investigation or even wide surgical excision.

Close links need to be made between clinical colposcopy and exfoliative cytology and histopathology. Ideally the colposcopist should be equally skilled in gynaecological pathology and in cytology, but in practice this combination is rare. An experienced, soundly based opinion is required especially when there is a question of conservative treatment. There is no place for inadequately trained colposcopists using the instrument on an occasional basis in small departments or hospitals. The technique with its clear service and important research components, should be based on selected major centres prepared to accept referred cases from surrounding smaller hospitals. We require relatively few colposcopists but they must be very well trained.

1 Hinselmann H. Verbesserung der inspektionsmöglichkeiten von vulva, vagina und portio. Munch Med Wochenschr 1925;72:1733.

2 Hinselmann H. Einführung in die kolposkopie. Hamburg: Hartung, 1933.

3 Stafl A. Colposcopy. Clin Obstet Gynecol 1975;18:195-213.

- Papanicolau GN, Traut HF. Diagnosis of uterine cancer by vaginal smear. New York: Commonwealth Fund, 1943.

b Richart RM. The patient with an abnormal pap smear-screening techniques and management. $N$ Englf Med 1980;302:332-4.

- Coppleson M. Colposcopy. In: Stallworthy J, Bourne G, eds. Recent advances in obstetrics and gynaecology. 12th ed. Edinburgh: Churchill Livingstone, 1977:155-87.

7 Townsend DE, Ostergard DR. Cryocauterization for preinvasive cervical neoplasia. F Reprod Med $1971 ; 6: 171-6$.

8 Briggs RM. Dysplasia and early neoplasia of the uterine cervix. A review. Obstet Gynaecol Surv $1979 ; 34: 70-99$.

- Anderson AF. The Van-Watson colposcope. Lancet 1962;ii:813-4.

10 Coppleson $M$. The value of colposcopy in the detection of preclinical carcinoma of the cervix. Three years' experience at King George V Memorial Hospital, Sydney. Fournal of Obstetrics and Gynaecology of the British Empire 1960;67:11-23.

11 Coppleson M. Colposcopy, cervical carcinoma in situ and the gynaecologist. Based on experience with the method in 200 cases of carcinoma in situ. fournal of Obstetrics and Gynaecology of the British Empire 1964;71: 854-70.

12 Jordan JA. Cancer of the cervix uteri with particular reference to cytology. Practitioner 1969;202:351-62.

13 Singer A. The uterine cervix from adolescence to the menopause. $\mathrm{Br} \mathcal{F}$ Obstet Gynaecol 1975 ;82:81-99.
14 Crompton AC, Langley FA. Epithelial abnormalities of the cervix uteri. London: Heinemann, 1973.

15 Kirkup W, Singer A, Hill AS. The accuracy of colposcopically directed biopsy in patients with suspected intraepithelial neoplasia of the cervix. Br $\mathcal{F}$ Obstet Gynaecol 1980;87:1-4.

\section{"New" cardiopulmonary resuscitation}

Cardiopulmonary resuscitation is one of the few lifesaving procedures in medicine; so when fundamental changes are proposed in the way in which such procedures are conducted it becomes an important issue for any doctor. The superiority of expired air resuscitation over manual methods (Holger Nielson, Silvester Brosch) has been proved by comparison of arterial oxygen levels in medical student volunteers subjected to the various methods. ${ }^{1}$ Nevertheless, while clinical evidence has firmly established the place of expired air resuscitation for the support of ventilation, no such evidence exists to resolve arguments over the correct way to support circulation.

Two decades ago Kouwenhoven and his colleagues at Johns Hopkins Hospital showed that a peripheral pulse could be generated from an arrested heart by manual compression of the chest wall. ${ }^{2}$ The quality of cardiac massage was frequently assessed with a finger on the femoral pulse, but-as MacKenzie et al pointed out-this pulsation resulted from a systolic pressure wave and did not necessarily mean that there was forward flow of blood. ${ }^{3}$ The pulse wave was attributed to emptying of the heart by squeezing it in a sandwich formed by sternum and spine. Recent work by Rudikoff et $a l^{4}$ and Chandra et $a^{5}$ has clearly shown that this explanation is just not true.

The recent "Wolf Creek II" meeting on cardiopulmonary resuscitation discussed the scientific basis for providing modifications in cardiopulmonary resuscitation, every bit as revolutionary as Kouwenhoven's first observations. Two fundamental questions needed to be answered. Firstly, if the heart is considered to be a passive chamber, how does external compression cause forward blood flow rather than flow in both directions along the arteries and back up the thoracic veins? Secondly, how is optimal blood flow to be obtained ? Werner and his colleagues had used two-dimensional echocardiography to show that during chest compression (systole) the atrioventricular valves remain open. Regurgitation of blood is prevented by venous valves at the superior thoracic inletbeautifully demonstrated by Criley with cineangiography. During relaxation (diastole) only the aortic valve remains competent, preventing blood from flowing back into the left ventricle.

Argument remains whether the chest and all the hollow vessels within it constitute the primary pump, or whether this is the heart alone. Nevertheless, Weisfeldt supported the idea of the chest as a pump by showing that forward blood flow is augmented when intrathoracic pressure is increased by inflating the lungs concordantly with compression of the chest instead of discordantly, as is currently recommended. Most of the cardiopulmonary experts agreed with the implications of earlier work suggesting that chest compressions should be delivered more slowly than $60 / \mathrm{min}$, ensuring that at least half of the cycle is spent in systole. ${ }^{6}$

"New" cardiopulmonary resuscitation may well prove an important therapeutic advance but it is largely untried in man. 
Inflation of the chest with high intrathoracic pressures inevitably results in gastric distension with an unacceptable increase in the chance of vomiting. This problem may be overcome with the use of a cuffed endotracheal tube or perhaps an obturator airway in the oesophagus ${ }^{7}$ - provided that an adequate seal is made with the mask at the face.

1 Nolte H. A new evaluation of emergency methods for artificial ventilation. Acta Anaesthesiol Scand 1968;29, suppl:111-25.

2 Kouwenhoven WB, Jude JR, Knickerbocker GG. Closed-chest cardiac massage. FAMA 1960;173:1064-7.

${ }^{3}$ MacKenzie GJ, Taylor SH, McDonald AH, Donald KW. Haemodynamic effects of external cardiac compression. Lancet 1964 ;ii :1342-5.

4 Rudikoff MT, Maughan WL, Effron M, Freund P, Weisfeldt ML. Mechanisms of blood flow during cardiopulmonary resuscitation. Circulation 1980;61:345-52.

- Chandra N, Rudikoff M, Weisfeldt ML. Simultaneous chest compression and ventilation at high airway pressure during cardiopulmonary resuscitation. Lancet $1980 ; \mathrm{i}: 175-8$

- Taylor GJ, Tucker WM, Greene HL, Rudikoff MT, Weisfeldt ML. Importance of prolonged compression during cardiopulmonary resuscitation in man. N Engl F Med 1977;296:1515-7.

7 Don Michael TA, Hotfon AS. The oesophageal obturator airway: a new device in emergency cardiopulmonary resuscitation. $\mathrm{Br} M e d \mathcal{F} 1980$; 281:1531-4.

\section{Bronchial adenomas}

Bronchial adenomas form a heterogeneous group accounting for somewhere between $1 \%$ and $6 \%$ of all primary lung tumours. $^{1-4}$ They are a continuing source of error and confusion in diagnosis. Though traditionally regarded as benign, more realistically they should be viewed as tumours of varying degrees of low-grade malignancy. Adenomas are derived from the duct epithelium of bronchial mucous glands and are usually either carcinoids or tumours of salivary-gland type.

Carcinoids account for about $90 \%$ of most series ${ }^{4-6}$ and generally arise centrally in the trachea or main bronchi. Often they present with features of an endobronchial polyp, but extensive infiltration of surrounding lung is common. The characteristic features seen with gut carcinoids-cyanotic flushing, abdominal cramps, diarrhoea, oedema of the face and arms, and wheezing and dyspnoea-are rare with primary lung tumours, occurring in only about $2 \%$ of cases. ${ }^{5}$ When the heart valves are affected by primary lung carcinoids the lesions occur in the left heart ${ }^{2}$ rather than in the right heart, as with gut carcinoids and secondary deposits.

About two-thirds of the tumours of the salivary-gland type are cylindromas. Typically these, too, are central tumours, often encircling the airway and infiltrating extensively into surrounding lung. They are second only to primary carcinomas in incidence as tumours of the trachea. Most of the remainder of the salivary-gland tumours are mucoepidermoid adenomas. Pleomorphic adenomas, resembling mixed parotid tumours, are very rare.

Bronchial adenomas usually present for diagnosis at a much earlier age than carcinomas, commonly before the age of 50,48 and the sex incidence is more nearly equal. Cough and haemoptysis are the first symptoms in around half the patients; often the chest radiograph is normal at that time. Another common pattern of presentation is with infection distal to obstruction by the tumour, causing lobar or segmental collapse and occasionally bronchiectasis, lung abscess, or empyema. Obstructive emphysema with overinflation of a segmental lobe may also occur distal to an adenoma. Peripheral adenomas tend to declare themselves much later and may be discovered as an incidental finding on chest radiography.
Early diagnosis of this group of tumours is essential if local destructive damage and distant metastases are to be avoided. Suspicion should be aroused in any patient with haemoptysis or recurrent chest infections, especially with a normal chest radiograph. Since almost all these tumours are visible at bronchoscopy this is the investigation of choice, but caution is necessary: many have a highly vascular stroma and bleed profusely on biopsy. If fibreoptic bronchoscopy is used an endotracheal tube or rigid bronchoscope must immediately be available to deal with bleeding.

Whenever feasible the treatment of bronchial adenoma is surgical. ${ }^{4}$ Sleeve resection of the tumour may sometimes be possible, but lobectomy or even pneumonectomy may be necessary because of extensive spread. Favourable responses to radiotherapy have been reported with cylindromas regarded as unresectable. ${ }^{910}$ Where the primary tumour can be resected the prognosis is good: prolonged survival is possible even with distant metastases, because these tumours grow so slowly.11

1 Gibbons JH, Nealon TF. Neoplasms of the lungs and trachea. In: Gibbons JH, ed. Surgery of the chest. Philadelphia: WB Saunders, 1962. 2 Thompson VC. Tumours of the lung. In: Perry KMA, Sellors TH, eds. Chest diseases. Vol 2. London: Butterworth, 1963.

3 Arrigoni MG, Woolmer LB, Bernatz PE, Miller WE, Fontana RS. Benign tumours of the lung. A ten-year surgical experience. $f$ Thorac Cardiovasc Surg 1970;60:589-99.

4 Lawson RM, Ramanathan L, Hurley G, Hinson KW, Lennox SC. Bronchial adenoma: review of 18-year experience at the Brompton Hospital. Thorax $1976 ; 31: 245-53$.

5 Payne WS, Fontana RS, Woolner LB. Bronchial tumours originating from mucous glands. Current classification and unusual manifestations. Med Clin North Am 1964;48:945-60.

${ }^{6}$ Markel SF, Abell MR, Haight C, French AJ. Neoplasms of bronchus commonly designated as adenomas. Cancer 1964;17:590-608.

${ }^{7}$ Melmon KL, Sjoerdsma A, Mason DT. Distinctive clinical and therapeutic aspects of the syndrome associated with bronchial carcinoid tumours. Am $\mathcal{F}$ Med $1965 ; 39: 568-81$.

8 Bower G. Bronchial adenomas. A review of twenty-eight cases. Am Rev Respir Dis 1965;92:558-63.

9 Thomas CP. Benign tumours of the lung. Lancet 1954 ;i:1-7.

10 Vieta JO, Maier HC. The treatment of adenoid cystic carcinoma (cylindroma) of the respiratory tract by surgery and radiation therapy. Diseases of the Chest $1957 ; 31: 493-511$.

11 Zellos S. Bronchial adenoma. Thorax 1962;17:61-8.

\section{Improving the surgical management of biliary atresia}

For the infant with biliary atresia the only hope of prolonged survival lies in early diagnosis and effective surgery. The diagnosis must be considered in any infant in the first weeks of life who becomes jaundiced with dark, bile-containing (as opposed to normal, colourless) urine. Such infants always have some hepatobiliary disease; they have a high risk of intracranial bleeding from lack of vitamin $\mathrm{K}$, and require urgent investigation to exclude treatable conditions such as galactosaemia or septicaemia. When these and other common genetic causes, such as alpha-1-antitrypsin deficiency, have been excluded and the stools lack bile pigment biliary atresia becomes a distinct possibility.

To what extent is biliary atresia treatable surgically? A review by Psacharopoulos and co-workers ${ }^{1}$ of 47 consecutive infants operated on by one surgeon at King's College Hospital, London, from July 1973 to December 1978, reported 17 survivors aged between 3 and 65 months who were symptomfree with normal growth and normal serum concentrations 